\title{
The Plight on the Development of P2P Online Lending and the Countermeasures Using Blockchain
}

\author{
Xiyang $\mathrm{Su}^{1, *}$ \\ ${ }^{1}$ SDLD COLLEGE LONDON, LONDON SE1 7FX, UK \\ ${ }^{*}$ Corresponding author. Email: Xiyangsu19@dld.org
}

\begin{abstract}
Peer-to-peer internet lending is a new form of lending. However, a crisis of trust has been triggered owing to the low threshold of the industry and the information asymmetry amongst three types of participants (lenders, borrowers and P2P online lending platforms). The data of online lending platforms are inaccurate, unreliable and incomplete, which leads to a decline of investor' $\mathrm{s}$ confidence in the investment. Although all aspects of the regulatory system are improving by the Chinese government to rectify the problematic platforms, it would be difficult to rebuild the trust in the relationship between lenders and borrowers. Therefore, one of the crucial factors to restore trust would be: identifying sources of the crisis of confidence. This paper is divided into four parts: the first part sorts out the development status of P2P online lending platforms; the second part introduces operation modes of P2P online lending industry by combining the core concept of $\mathrm{P} 2 \mathrm{P}$ internet loan, compares the lending services of traditional banks and e-commerce enterprises with that of P2P online lending, and reveals the differences in investing and financing activities between China and developed countries; The third part mainly analyses the difficulties faced by P2P online lending industry from four aspects which are the acquisition, review, analysis and finally the contractual relationship between lenders and borrowers. The fourth part combines blockchain technology, user portrait and smart contract to provide corresponding countermeasures to the existing difficulties.
\end{abstract}

Keywords: P2P online lending, Blockchain, Smart contract, User portrait

\section{INTRODUCTION}

Developed countries have many financial channels, while China has relatively narrow financial channels, a launch of P2P online lending platforms has attracted the attention of a large number of fund seekers. In 2007, Paipaidai, the first $\mathrm{P} 2 \mathrm{P}$ online lending platform in China was established, marking that the P2P online lending industry in China has entered an embryonic stage. With the rapid growth of the number of P2P platforms, a large number of problematic platforms are exposed. Many online lending companies have management and technology risks. From the perspective of management, $\mathrm{P} 2 \mathrm{P}$ practitioners lack professional knowledge in risk control and risk assessment and are difficult to deal with emergencies in an operation process. The information technology control of the platform is not strict, and there are risks such as information leakage and hacker intrusion. The issues such as that P2P platform owners fled with money collected from investors and that borrowers failed to repay the debt within the prescribed period time emerged in an endless stream, which caused serious trust crisis. By March 2019, the total number of platforms has reached 6,606, and the total number of problematic platforms has reached 2,923. Although after 2015, the Chinese government agencies issued corresponding policies to control and improve the supervision of problematic platforms, and the number of platforms declined significantly for three consecutive years, investors' confidence did not increase significantly. In December 2019, the transaction volume of P2P online lending industry was 42.889 billion yuan, 60.818 billion yuan less than that of January 2019.1 (Wangdaizhijia) The decline reflects lenders' wait-andsee attitude toward P2P lending platforms. Different from the online lending services provided by traditional financial institutions, P2P online lending has the special nature of "point-to-point". As the "central server", traditional financial institutions can grasp the detailed and reliable user information through customer's capital circulation history, credit rating, financial account status, etc. P2P online lending platform, as an information intermediary, has limited ability in data acquisition and audit, so it cannot establish reliable user 
files. After the outbreak of a trust crisis, it is difficult to establish the trust in the relationship between lenders and borrowers. The fundamental reason is that investors cannot ensure whether the information provided by platforms is true or not, and they hold a hesitant attitude towards the risk control ability of $\mathrm{P} 2 \mathrm{P}$ platforms. The combination of blockchain technology and $\mathrm{P} 2 \mathrm{P}$ online lending can effectively solve the problem by exploit blockchain features such as non-tampering and de-trust. Those features can enhance the credibility of data presented on platforms.

\section{ANALYSIS OF THE DEVELOPMENT AND OPERATION MODES OF P2P LENGDING PLANTFORMS}

\subsection{The difference between P2P online lending and traditional internet lending}

\subsubsection{Introduction to P2P online lending}

P2P stands for "Peer to Peer", and P2P lending is the abbreviation of $\mathrm{P} 2 \mathrm{P}$ online lending, a kind of internet finance, which allows free financing or investing between lenders and borrowers. P2P was originally a computer technology designed to solve network congestion, and its decentralized nature was used to reduce the pressure on central servers. The combination of P2P technology and online lending services makes it possible for lenders and borrowers to build a contractual relationship based on free negotiations including contract details such as interest rate, loan period, etc. P2P lending has more powerful bargaining strength comparing to the traditional centralized management of financial institutions. Meanwhile, the features of low threshold, simplified lending procedures and the matching function make the overall lending services more flexible. Thereby, P2P lending gets the favour of small-to-medium enterprises and private lenders. However, due to the unprofessional risk control level of platforms themselves, P2P online lending industry currently provides only a small amount of loans.

\subsubsection{Banking and internet supply chain finance platforms}

In essence, banks and e-commerce enterprises provide their existing or potential customers online lending services to cope with the impact of internet finance on traditional offline finance. There is only one kind of fund providers on each of those two types of financing modes, namely banks or e-commerce enterprises. The lending services provided by banks and enterprises are on one-to-many basis. The expansion of electronic business will increase the investment income for banks and e-commerce enterprises. Moreover, the brand influence of platforms can effectively attract more potential customers. As banks and e-commerce enterprises have more detailed customer information, trust risks can be effectively decreased. Compared with $\mathrm{P} 2 \mathrm{P}$ online lending platforms, banks and e-commerce enterprises have higher requirements on the credit rating of borrowers themselves.

\subsection{Three main operation modes}

\subsubsection{Pure online mode}

P2P lending platforms only play the role of information intermediary under this mode. The platform itself does not have customer information but mainly relies on the information uploaded by lenders and borrowers to integrate and select data. Platforms adopting pure online mode will post borrowing requirements of qualified borrowers on their website for investors to choose from. Pure online operation mode requires $\mathrm{P} 2 \mathrm{P}$ online lending platforms to have high-risk control ability and requires online lending practitioners to have plentiful risk management knowledge due to the fact that the pure online operation mode does not require platforms to conduct an offline on-the-spot assessment. It usually takes a long time to establish the trust in the relationship between lenders and borrowers, which could lead to lower matching efficiency.

\subsubsection{Credit assignment mode}

In the operation mode of credit assignment, besides borrowers and investors, there is also a third party ( $\mathrm{P} 2 \mathrm{P}$ lending platforms or micro-credit companies). In this mode there is no direct contractual relationship between borrowers and lenders, but a third party lends to borrowers in advance to form the creditor's rights, and then the third party splits the creditor's rights or transfers them to investors completely. The participation of the third party mitigates trust risks between investors and borrowers, and the third-party conduct offline audit to authenticate the information of borrowers. However, it should be noted that the creditor's rights should be formed before a transfer of funds, otherwise the third party may be suspicious of conducting illegal fundraising.

\subsubsection{Guarantee mode}

To improve investors' confidence in participating in $\mathrm{P} 2 \mathrm{P}$ lending, the guarantee mode is introduced. This means that a $\mathrm{P} 2 \mathrm{P}$ online loan platform or a third-party professional guarantee corporation provides guarantee services. There are two guarantee modes. One is that third-party guarantee corporations which P2P lending platforms cooperate with provide guarantee services for customers. Such professional guarantee corporations usually have professional knowledge background and will carry out offline audit work, which can effectively reduce the investment risks of investors. However, 
professional guarantee companies will charge a certain amount of commission fee. Normally, guarantee companies have stronger bargaining power comparing to $\mathrm{P} 2 \mathrm{P}$ lending platforms. Therefore, $\mathrm{P} 2 \mathrm{P}$ online lending platforms may be in a weak position and thus lose pricing power. Another mode is that $\mathrm{P} 2 \mathrm{P}$ online lending platforms themselves guarantee the lending business. $\mathrm{P} 2 \mathrm{P}$ platforms promise to protect investors with the fund of those platforms. Nonetheless, in P2P online loan industry, the amount of net assets of most online loan companies may be insufficient to support the guarantee amount, and a problem of excessive guarantee may occur.

\subsection{Differences in investing and financing activities between China and developed countries}

Direct financing accounted for more than $80 \%$ of the stock social financing structure in the United States in 2017, while in China, on the contrary, indirect financing exceeded $80 \%$. By the end of 2017, the number of micro, small and medium-sized enterprises accounted for $90 \%$ of the total number of enterprises, contributing $50 \%$ of tax revenue, $60 \%$ of GDP, $70 \%$ of patents and $80 \%$ of employment. However, the loan balance of small and micro enterprises only accounted for about $25 \%$ of the loan balance of financial institutions 2. (Lin and $\mathrm{Fu}, 2019$ ) Banks prefer clients who can provide collaterals, which restricts the amount of loans for SMEs with limited collaterals. Therefore, China has a greater demand for P2P online lending, which will attract the participation of a large number of practitioners in the $\mathrm{P} 2 \mathrm{P}$ online lending industry and easily lead to a situation of mess. Additionally, investors in developed countries have more mature investment insights and have a clearer understanding of the risks of investment. Conversely, Chinese investors generally have little investment experience and weak risks awareness. They are not stable or rational in investment psychology.3 (Jiang, 2004) Most investors do not have sufficient understanding of the relationship between risk and return, and prefer avoiding principal loss.

\section{THE DEVELOPMENT PLIGHTS OF P2P ONLINE LENGING PLATFORMS}

\subsection{Limited access to information}

In China, a unified credit investigation system has not been formed, and there are still no perfect laws or regulations to enable personal credit investigation data to be shared amongst major financial institutions. P2P lending platforms, as information intermediaries, rely heavily on personal credit information. It is difficult for $\mathrm{P} 2 \mathrm{P}$ lending platforms to establish their credit investigation system and operate it independently.
Meanwhile, a lack of communication among banks, other major financial institutions as well as government departments makes it less likely to achieve resources sharing in the short run. As a result, $\mathrm{P} 2 \mathrm{P}$ platforms can only obtain personal credit information by depending upon the personal data uploaded by users, including marriage certificates, age and career information, to assess customer's credit rating. However, a research shows that borrower's credit rating has no influence on the prediction of its default rate, so it cannot be concluded that a borrower's credit rating could be a strong reference for credit risks.4 (Zheng, 2016) To sum up, the information acquisition sources of P2P platforms are limited and inefficient.

\subsection{The capability of user profiling auditing}

The auditing process of a $\mathrm{P} 2 \mathrm{P}$ lending platform is generally as follows: (1) Screen the information provided by borrowers and publish lending information of borrowers who provide complete information. (2) Conduct offline on-the-spot investigation on the authenticity of the information provided by borrowers. (3) Check the background information of borrowers to further verify the authenticity of the emergency contact information provided. (4) Review personal financial statements, bank statements, etc. to assess the borrower's ability to repay the debt.

However, that is an ideal audit process. P2P online lending platforms will not conduct an offline audit for every fund seeker with loan demand. In the current P2P lending industry, problematic platforms account for a large proportion of the total number of platforms, while those with professional risk control and assessment capabilities account for a small number of platforms. The decreasing turnover caused by a shrink of trading volume might not be enough to support a detailed offline investigation.

\subsection{Limited ability to analyse user data}

As information intermediaries, $\mathrm{P} 2 \mathrm{P}$ lending platforms play a very important role in integrating and analysing the collected user data to provide better matching services for borrowers and lenders. As a kind of financial infrastructure, internet finance largely relies on computer technology, such as big data. In the face of all kinds of information provided by borrowers, P2P lending platforms mainly take advantage of the audit ability of practitioners. This is because: (1) Most P2P platforms are not professional technology companies. (2) P2P platforms are independent of credit investigation systems of other financial institutions and e-commerce enterprises, which results in a situation that $\mathrm{P} 2 \mathrm{P}$ platforms cannot further analyse user information based on browsing preferences, financial management preferences and transfer methods on the internet. 
To sum up, P2P lending platforms do not exploit the benefits of big data on the internet. Compared with other financial institutions and e-commerce enterprises, P2P lending companies have a single form of data analysis and rely more on a manual audit. The resulting problems are low effectiveness, low accuracy and timewasting.

\subsection{The weak contractual relationship between investors and borrowers}

Finance is highly dependent on a contractual relationship. $\mathrm{P} 2 \mathrm{P}$ online lending is a subclass of finance and still has the essence of finance: credit relationship. As a new form of lending, $\mathrm{P} 2 \mathrm{P}$ online lending has no specific legislation to follow, resulting in different judicial standards for contract disputes on platforms.5 (Peng, 2018) The judgment on the contractual responsibilities and obligations of $\mathrm{P} 2 \mathrm{P}$ online lending platforms is not clear, which thus provides platform operators with opportunities to escape with money collected from investors. Thus, investors are likely to face huge credit risks.

\section{COUNTERMEASURES BASED ON BLOCKCHAIN TECHNOLOGY}

\subsection{Core concepts}

\subsubsection{Blockchain}

Blockchain is essentially a decentralized distributed accounting database. Each block contains a small proportion of the previous block. Thus the information is traceable. Each node realizes self-information verification, management and transmission, and it relies on a consensus mechanism to ensure that each node stores the same ledger. At the same time, based on the application of cryptography, each new block generation will be stamped with a timestamp and the blocks are connected in chronological order, thus forming a blockchain. Therefore, the blockchain is very tamperproof. Once a new transaction is initiated, it would be broadcast to each node. A block would be formed after nodes self-verify, confirm and finally package the transactions. Although transaction information is public, personal information is protected by a key in blockchain and is anonymous. The key in blockchain technology is a parameter on the cryptography basis, which includes a public key and a private key. The application of public keys and private keys further protects information security.

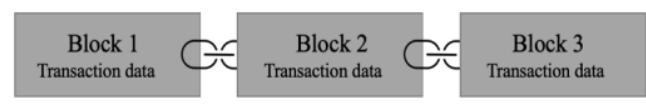

Fig. 1. Blockchain introduction

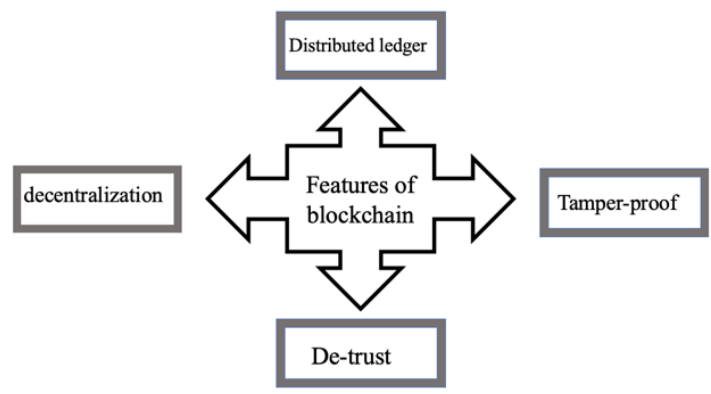

Fig. 2. Features of blockchain.

\subsubsection{Smart contract}

Smart contract is an application of blockchain technology. Compared with the traditional contract, the smart contract is a kind of computer technology. At the beginning of the establishment of smart contracts, the programmers input the code after borrowers and lenders have come to an agreement on contract details. Once the smart contract is confirmed, it cannot be changed, and the system will perform the contract obligations automatically. Besides, a smart contract is mandatory and de-trusted. The whole process of fulfilling the contract responsibility is automatically executed, and neither party can affect the execution of a smart contract.

\subsubsection{User profiling}

User profiling is a comprehensive model to build users portraits based on real data.6 (Hao and Chen, 2016) It is an effective tool to segment targeted customers, understand customer demands and design products. The establishment of user portrait is inseparable from the application of big data. In the internet era, online activities of customers would be recorded, such as browsing preference, staying time on a website and payment preference. Once the data is collected, customers are divided into segments with different characteristics through technical analysis. Enterprises would establish their user portrait databases according to product branding. 


\subsection{Cooperation of P2P lending platforms, traditional finance institutes and government agencies}

P2P lending, as a new form of internet finance, has many restrictions on the access to information and largely depends on the personal credibility of customers in the aspect of collecting user data. Under the combination of P2P lending and blockchain technology, $\mathrm{P} 2 \mathrm{P}$ lending platforms can cooperate with traditional financial institutions or government institutions. If a user applies for a business license in a government agency or opens an account in a bank, the government or bank uploads those information to blockchain. At the same time, traditional financial institutions or governments can also save information to their central management system for backup. Blockchain's timestamp technology can guarantee the authenticity of users' data, making it difficult to tamper with their personal information. Furthermore, users can choose whether to disclose their data to others. Users provide $\mathrm{P} 2 \mathrm{P}$ platforms with permissions to access to personal data including transaction records, bank statements, etc. when users need to borrow or lend. After collecting personal information, they establish customers' files and build user portraits by tagging users with "labels" -borrowing needs, past credit ratings, etc. With the new process of lending based on the application of blockchain, P2P platforms do not need to adopt the guarantee operation or the credit assignment operation mode as there are only two participants are needed which are lenders and borrowers. As a result, P2P lending essentially realizes “peer to peer" . As P2P lending platforms only serve as information transfer stations, and they provide only matching services which mean the platforms match fund seekers with fund providers, the lending business capabilities are mainly reflected in matching services which rely on a $\mathrm{P} 2 \mathrm{P}$ lending platform' $\mathrm{s}$ ability to analyse big data. The competition in the $\mathrm{P} 2 \mathrm{P}$ lending industry will become purer, shifting from the original competition of qualification and capital to the competition of technology. Only those platforms that have big data analysis technology or that have more practitioners who master both data analysis and professional online lending knowledge can stand out in the P2P lending industry. In consequence, a positive competition would encourage every $\mathrm{P} 2 \mathrm{P}$ platform to improve the quality and efficiency of matching services to survive.

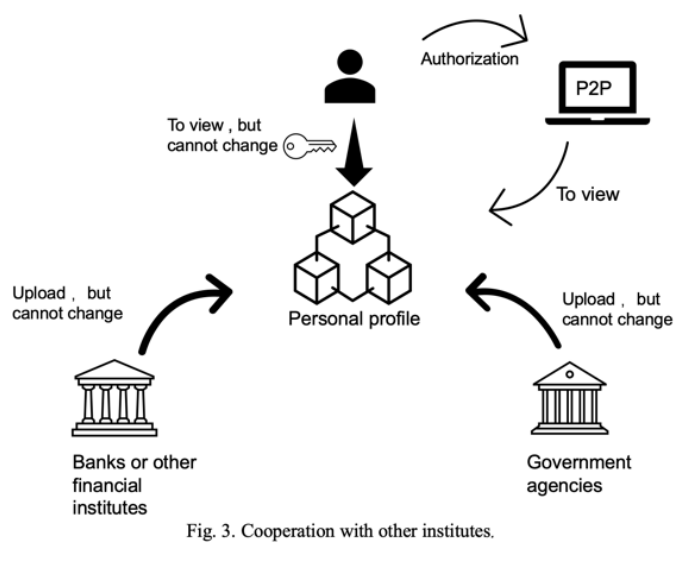

\subsection{Simplification of the audit process by using the de-trust feature of blockchain}

In the past, $\mathrm{P} 2 \mathrm{P}$ lending platforms not only provide matching services but also need to spend a lot of time and money to audit user information. The purpose of an audit is to protect the investment interests of both parties and reduce risks of default. It is difficult to establish an independent credit investigation database by $\mathrm{P} 2 \mathrm{P}$ platforms themselves since the financial institutes are unwilling to share the personal credit data of users. The limitation of credit investigation environment further increases the difficulty of an audit. Uploading every user' $s$ information onto the blockchain would simplify the audit process to check the authenticity of the user data. Users' certificates are issued by government agencies or financial institutions, and the possibility of information tampering by users is reduced by storing the certificate information on the blockchain through the government or financial institutions. P2P lending platforms exist in the blockchain as a role of third-party institutions. The lending information shared by users who have loan demand will be uploaded to the blockchain by platforms, and then broadcast to all nodes. When the user has a second loan demand in another platform, the targeted platform does not need to audit the user's past loan data as it only needs to ask for a permission from the user to view the information, which improves the service efficiency. In addition to simplifying the business audit process of P2P online lending, the government can also improve the supervision efficiency of online lending platforms. The regulatory authorities check on $\mathrm{P} 2 \mathrm{P}$ online lending platforms, including but not limited to: whether the platform is strictly positioned as an information intermediary; Whether to adhere to the principle of microfinance; and the authenticity of the report contents and data, etc.7 (China Banking and Insurance Regulatory Commission,2018)The government can quickly verify whether the loan transactions are legitimate by reviewing transaction records. In the meantime, the distributed ledger data of blockchain records the transaction address, amount and so on in 
detail, which allows the government to check whether the P2P platform adheres to the principle of small loan by checking the amount of money. P2P platforms cannot tamper with any information on the blockchain. Therefore, the regulatory authorities do not need to verify the authenticity of the platform data again, resulting in an improvement of audit efficiency.

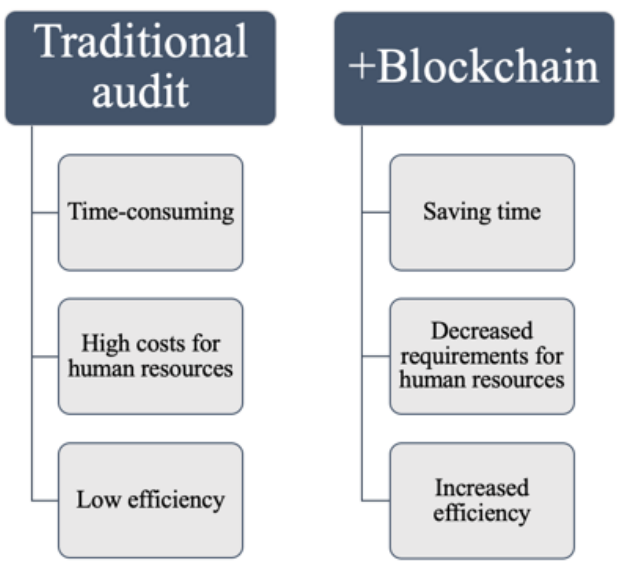

Fig. 4. Audit process comparation.

\subsection{Establishment of smart contracts to protect the interests of lenders and borrowers}

A weak contractual relationship often leads to the loss of investors' interests and causes damages to the reputation of $\mathrm{P} 2 \mathrm{P}$ platforms, which would restrict the development of P2P online lending industry. A good contractual relationship not only requires the signatory to have good contractual spirit but also requires close cooperation of the regulatory authorities, such as the improvement of relevant laws and regulations as well as punishment systems. Smart contracts have the ability of automatic execution. Except two parties signing the contract, there is no need for a third-party guarantee agency. Lenders and borrowers negotiate the contract terms including obligations, rights, etc. Programmers write smart contracts based on the negotiation. Once a smart contract has been formed, the contract will automatically carry out the terms until the contract expires. For example, after a borrower and a lender have negotiated the amount of loan, loan period and the interest rate, those contract details will be written into a smart contract. When the loan expires, the system will automatically transfer the principal and interest from the borrower's account to the investor's account. Regulatory authorities can check the operation of contracts to monitor lending businesses, and platforms can also track the progress of each loan transaction in real-time to develop better lending services for customers. Furthermore, the anonymity of the blockchain enhances the security of the personal data of trading parties. P2P platforms can benefit from a smart contract as they do not have to face various contract disputes. Meanwhile, investors do not have to worry about the risk that borrowers may flee with their money. It not only guarantees the firmness of a contract relationship but also improves the execution efficiency of the contract.

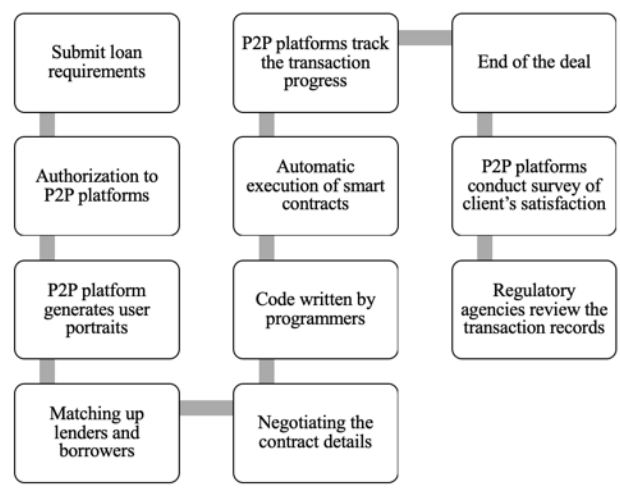

Fig. 5. A complete procedure of $\mathrm{P} 2 \mathrm{P}$ lending service on the combination with blockchain technology basis.

\section{CONCLUSION}

The combination of P2P online lending and blockchain ensures the authenticity and security of users , information in the aspects of data acquisition, storage and audit. The combination can effectively improve the confidence of lenders, solve the difficulties caused by a crisis of trust and reduce the risks brought by the imperfect regulatory system. However, these countermeasures have certain limitations. The application of the blockchain has higher technical requirements on $\mathrm{P} 2 \mathrm{P}$ lending platforms and even users themselves. For example, smart contracts are formed by manually written code which often becomes the goal of hackers. The application of blockchain not only requires the participation of $\mathrm{P} 2 \mathrm{P}$ platforms, lenders and borrowers but also requires the cooperation of traditional institutes and government agencies. Moreover, the distributed ledger has a core concept of decentralization which is completely different from the centralized operation mode that most institutes are using currently. Therefore, it will take a long time for departments to work closely together.

\section{REFERENCES}

[1] Wangdaizhijia.(n.d.). Net credit data. [online] Available at:https://shuju.wdzj.com/industrylist.html [Accessed 8 Nov. 2020].

[2] Lin, Y. and Fu, C. (2019). The direct financing led financial structure of the US is not suitable for China today. [online] Guancha News. Available at: https://www.guancha.cn/LinYiFu/2019_10_21_52 2077_2.shtml [Accessed 18 Oct. 2020]. 
[3] Jiang , X. (2004). Irrationality and Limited Rationality: An Empirical Study on the Investors' Behavior in Chinese Stock Market. PhD. Xiamen University.

[4] Zheng, Y. (2016). Research on credit Risk of P2P online lending borrowers in China. PhD. Henan University

[5] Peng, Q. (2018). Research on Legal Issues of P2P Online Lending Platform under Contract Law (M.A thesis, Guangdong University of Foreign Studies).https://kns.cnki.net/KCMS/detail/detail.as px ddbname $=$ CMFD201901 $\&$ filename $=101887053$ 1.nh

[6] Hao, S. and Chen, J. (2016). In the data era, user portraits help enterprises achieve precision marketing. China Collective Economy, [online] Volume (04), p.61-62. Availabe at: https://kns.cnki.net/kcms/detail/detail.aspx?FileNa me $=$ ZJTG201604035\&DbName $=$ CJFQ2016 [ Accessed 8 Nov. 2020]

[7] Hunan local financial supervision and Administration, (2018). Notice on carrying out compliance inspection of P2P Network and network Lending Institutions. Hunan:China Banking and Insurance Regulatory Commission, p.2. 